\title{
Bottom-Up Lean Practice Deployment in a Global Setting: A Case Study from the Pharmaceutical Industry
}

\author{
Sara LINDERSON ${ }^{\mathrm{a}, 1}$, Seyoum Eshetu BIRKIE ${ }^{\mathrm{a}}$ and Monica BELLGRAN ${ }^{\mathrm{a}}$ \\ ${ }^{a}$ Department of Sustainable Production Development, KTH Royal Institute of \\ Technology, Sweden.
}

\begin{abstract}
In view of major social changes, such as the growing climate crisis, increased external expectations on the production sector demand an industrial transformation. Since transformations call for innovation, new lean practices will emerge locally at sites in production networks to cope with new challenges. But, how can new local lean practices be deployed for utilization by other parts of the company? Global production companies strive for broad over-all improvements within the network. This is often approached through a top-down deployment of a global lean framework, using various mechanisms. Lean standard development is a central mechanism for transferring best practices and lean knowledge within a corporate group. Anchored to well-established theories, such as innovation diffusion and plant network theory, prior lean transfer studies often take a cascading top-down perspective. In contrast, this study aims to explore lean practice diffusion through a bottom-up perspective. It explores the process of deploying new local lean practices to the corporate network. The empirical findings are based on a single case study at the pharmaceutical company AstraZeneca. The findings indicate that the bottom-up deployment process can be explained by four phases, 'Piloting', 'Branding', 'Codifying Knowledge' and 'Making a Product' that varies in degree of practice adaptation. The lean practice incorporation to a global lean framework is discussed around three conceptual deployment approaches called, 'template', 'standard' and 'product' deployment. The empirical insight contributes to the body of global lean literature by providing a more dynamic view of global lean frameworks, of which development depends on the underlying processes such as bottom-up practice incorporation. It also provides practitioners in global lean settings with valuable insight and a possibility to review internal global-local deployment processes within a corporate group to increase intra-organizational learning.
\end{abstract}

Keywords. Lean management, production system, multinational corporation, practice incorporation, lean deployment

\section{Introduction}

The general increased attention for environmental impact highlights the need for a green transformation into a more environmental-friendly business. Thus, in contrast to the main focus on financial perspectives in lean management, environmental aspects (e.g. reduction of the company's' $\mathrm{CO}_{2}$-footprint) will be as important to address. For example, the EU president emphasized the need to further increase $\mathrm{CO}_{2}$ reduction targets from

\footnotetext{
${ }^{1}$ Corresponding Author. linderso@kth.se
} 
$40 \%$ to $50 \%$ in the European region by 2030 to be sufficient [1]. This indicates tighter common legislation in the future to accomplish the target. In other words, a company's environmental impact is not solely a question of social and environmental responsibility but important for future competitiveness together with the financial aspects. Given the aforementioned view, it is not surprising that more research is directed towards the integration of lean and green management. This study focuses on an investigation of the underlying processes that enable efficient corporate lean management that may be seen in connection with environmental impact reduction as a way to increase resource efficiency and competitiveness.

Nowadays, lean is applied as a corporate management system in many corporate groups worldwide, often with a specific dialect conceptualized into the company-specific production system (XPS) [2]. Managing a corporate group is not the same as managing a single production site. It involves several aspects to consider, such as developing a corporate lean framework and deciding upon the level of harmonization within the corporate group. For example, standardization of management practices in the corporate lean framework can be structured as mandatory for an adopting production site to comply with, or be optional. Developing lean standards is a central mechanism when diffusing lean knowledge (i.e. practice deployment) within the corporate network.

In view of the need for industrial transformation, new lean practices will emerge, if not yet embedded in the current corporate frameworks for lean management. The purpose of this study is to explore the bottom-up deployment process of a new lean practice in a global lean context. The exploration of an industrial case of practice deployment in a global lean context highlights influential variables that are specific for the global lean context. The empirical findings provide an increased understanding of aspects to consider (e.g. the relationship between practice deployment and practice adaptation) to decrease undesirable effects between global and local levels within a corporate group. Increased tension between local-global levels due to the 'misalignment' of practices within a corporate group is an example of that [3]. Thus, exploration of the bottom-up incorporation process of new local lean practices is relevant to ensure efficient lean practice diffusion within a corporate group.

\section{Theoretical framework}

\subsection{The industrial transformation calls for new lean practices}

Manufacturing companies are under strong stakeholder pressure, for example, to meet the tighter $\mathrm{CO}_{2}$ reduction targets. Such pressure may also apply for the existing management of the production systems to retain competitive advantages. Logically, strategic plans will include new requirements and be revised frequently, followed by exploiting existing company-specific competencies and resources. Because one of the essential benefits of a global company is the transnational use of its intra-company resources, the deployment of 'best practices' within the company's network is of importance for competitive advantage [4], [5]. It demands efficient intra-organizational processes, including both global and local levels, for continuous practice development within the corporate network.

Most production companies have many years of experience of a lean management system, commonly achieved through a company-specific production system conceptualized with inspiration from the Toyota Production System. Lean as a concept 
has been difficult to define [6], however, our view of a corporate lean management system in this study is aligned with the 'XPS conceptualization' presented by Netland [2]. A corporate lean management system consists of a set of principles and processes often presented with a company-specific framework [7], here called a global framework. A cascading deployment process of a global framework can be explained as a 'roll-out' [8]. However, the top-down corporate perspective is rarely combined with a bottom-up process view. Since local production sites are likely to contribute to a company's global framework based on experiences gained during practice execution, this study views global frameworks as dynamic. It is, therefore, necessary to have intra-organizational processes to enable the continuous development of a global framework.

The above mentioned dynamic view calls for innovative lean practices (henceforth lean practices), here defined as; new lean practices to the company-specific global framework that gives significant value when implemented [9]. A new lean practice is viewed as a new process of actions that supports compliance to general lean principles [7], e.g. kaizen, problem solving, and value stream mapping. Examples of combining financial and environmental aspects in practices can be found in previous research, such as 'eco-efficiency' [10] and 'green value stream mapping' [11]. This study uses an example of an improvement event, called kaizen in lean production, which is useful for identifying and eliminating waste systematically in production [7].

\subsection{Practice development involves the construction of standards}

An interest in taking a corporate perspective in lean management research has emerged over the last years, see examples in Figure 1 [12]-[15]. These previous studies take mainly a top-down approach, overlooking the bottom-up view in a global lean setting (see Figure 1). The challenging task of deploying (or rolling-out) global improvement programs efficiently to a network of dispersed production sites is recognized. However, to understand the interplay with local production sites, a top-down view needs to be combined with the view of sites in a global lean context, i.e a bottom-up perspective.

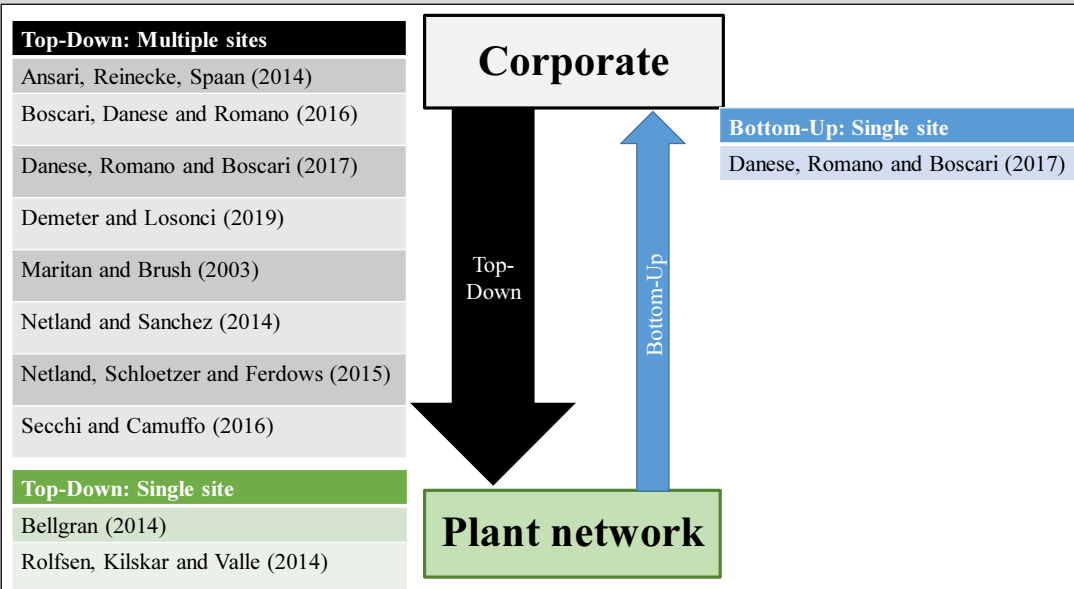

Context: Lean Management in corporate groups (e.g. deployment of improvement programs, lean transfer process, lean knowledge transfer).

Figure 1. Examples of existing global lean literature to illustrate the dominant top-down view in previous studies. 
Managing knowledge diffusion across a corporate production network is a complex task due to the heterogeneousness among the production sites. As a way to aim for broad performance improvements, standards are constructed as a tactic to exploit intraorganizational knowledge. 'Standards' are here defined as codified knowledge for lean processes and methods with the attempt to create a baseline with the latest known 'best practice'. Construction of standards is part of method development, or as Secchi and Camuffo [8] describes it, a 'knowledge duplication strategy', to diffuse new lean practice knowledge. The standards are traditionally deployed by a top-down approach through various mechanisms. For example, globally designed improvement programs [8], [16], which are deployed broadly to all production sites. The standards could also be integrated as a part of the company's' 'toolbox' which are deployed through other network infrastructures [17]. However, regardless of the deployment mechanism, standards are very unlikely adopted without adaptations since they tend to be modified to 'fit' the specific context [18]. Deciding on the degree of standardization of practices relates to balancing between the two opposites: modification being fully avoided (i.e. practice adoption), or allowing modifications (i.e. practice adaptation) [18]. A standard that is too strict and not possible to morph could lead to superficial implementation, whereas too many modification risks compromising the underlying purpose of the practice [16], [19]. Thus, determining the level of standardization is a challenging task due to intraorganizational tensions caused by balancing the two extremes.

Secchi and Camuffo [8] argue that three dimensions are of importance for effectiveness and efficiency in top-down cascading processes (i.e roll out); 1) the knowledge duplication strategy (i.e. degree of codified knowledge in standards), 2) the degree of decision-making decentralization, and 3) the co-existence of knowledge exploration and exploitation on production site level. The current study aims to explore if the same dimensions are important from the perspective of a bottom-up lean practice deployment process. Despite the relevance of understanding the bottom-up approach in a global lean setting, the bottom-up view is seldom given enough attention. An important exception is a study by Danese et al. 2017 [19], that presents three different lean transfer approaches connected to local, global, and global-shared. The distinction of the local lean transfer approach was partly because lean standards being developed based on experiences at one single production site to be subsequently deployed further within the production network. However, the local transfer approach highlighted was based on a company case with the absence of a shared corporate lean program (ibid.).

Relating to the above mentioned three approaches, this paper contributes to the gap when local lean practices are transferred to a shared and common global framework (i.e. a local-shared approach). However, this study focuses solely on the variable of lean standard development. More exactly, the purpose of this study is to understand the process of how locally developed innovative lean practices were included in the shared company's global framework (i.e practice incorporation). 


\section{Methodology}

\subsection{Case selection and company description}

In a scattered production network where each site has its context, larger sites have, for example, often many support functions, and therefore more development resources for project cooperations. The case study was selected based on a pre-study at a large production site previously involved in external collaboration projects. Based on the identified intention to deploy a new successful lean practice, the case was selected for this study. The production site as part of a global corporate group applying a common lean framework and they wanted to investigate how this new lean practice could be integrated into the existing lean framework.

This paper presents empirical findings from the process of incorporating a lean practice called 'Green Kaizen' which was based on a method called Green Performance Map, developed in a research project with participating companies from the automotive industry [20]. The case study company, AstraZeneca, is a large pharmaceutical corporation with about 14.500 employees working at 28 production sites on six different continents. The production sites vary in size, products, production technology, and previous experience with lean production. The production system, AstraZeneca Supply System, is highly inspired by the Toyota Production System and Six Sigma. The AstraZeneca Supply System is managed centrally at the company headquarters, to provide a common lean framework, which is shared by the entire network of production sites.

\subsection{Research approach}

To understand the lean practice incorporation process, a qualitative case study approach was selected since it provides the rich insight needed to capture both decisions and intentions when deploying a lean method [21], [22]. Investigation of a case allows for understanding the intra-organizational relationships in the non-explicit process of practice incorporation and was, therefore, found appropriate for the exploratory purpose of this study. However, delimitations of the approach could be found regarding generalization of the explored incorporation process since the influence of the companyspecific culture was difficult to control. However, the rich case description provided in this study contributes with contextual insights valuable for understanding the influence of other variables which to some extent makes up for the disadvantages. In other words, some background variables could be controlled in a single case through a detailed understanding of the company context. The data was collected with a mixed-method approach by semi-structured interviews, documents, and observations during information meetings. The focus of the interviews was mainly on the intentions behind the decisions and actions of the practice deployment. Company documents and two master theses [23], [24] were also included in the data collection and analysis to deepen the understanding of the new lean practice and adaptation of the practice that was acknowledged during the study, as well as for data triangulation.

Procedural rigor of the data collection was assured by the usage of audio recordings during interviews, observation notes, and systematic journal notes. All data used for this study was triangulated with support from the mixed-method approach and respondent validation [25]. The data was analyzed abductively by a coding technique inspired by Gioia et al. [26] with the purpose to capture emerging categories jointly with the provided 
theoretical framework. The dimension of practice deployment was determined early in the pre-study. Thereafter, the data was coded with initial simple concepts that emerged into themes, and later constituting the four phases described in the findings (section 4). Along with the analysis, the findings indicated that the phases were mainly relating to the dimension of practice adaptation. Beyond the empirical findings, three conceptual bottom-up deployment approaches were constructed to support the analysis (section 4.2).

\section{The case study}

This section presents an account of our observations with a narrative involving both the specific case context (section 3.1) as well as the decisions and intention to deploy 'Green Kaizen' as an innovative lean practice further in the organization (section 3.2).

\subsection{Case description}

\subsubsection{Global context}

A global corporate lean program started in 2010 followed by several versions of global governance structures. The latest one was initiated in 2015 and is considered to be a more sophisticated attempt, partly because of the well-communicated explicit strategic plan for the lean transformation. The case company aims explicitly for central global governance of the lean system combined with decentralized local execution of deployment. The corporate lean management system includes comprehensive strategic targets, lean maturity assessment, and capability development programs. Deployment agents, i.e. lean practitioners, are organized at a global, regional and local level. A global framework, designed by the global lean office in 2016, serves as a common base. It comprises standards for lean practices in a global framework. A network infrastructure to bring together experiences as a base for development as well as deploying information, called business process management (BPM), is extensively used. In addition to other central business processes, some lean practices are categorized as processes in the network infrastructure, for example, 'problem solving', or 'continuous improvement'. The BPM infrastructure works as the main mechanism for practice development and best practice diffusion through different layers of network constellations locally, regionally and globally. Standards are created based on knowledge shared in the networks.

\subsubsection{Local site context}

The case study (ongoing at the time of this writing) is conducted at one of the largest production sites with a long history of lean production starting around the year 2006 on a site level. The company headquarter is located in another country. The internal lean community at the case production site has several years of experience with developing standards for lean practices and had, until the year 2019, a local lean framework parallel to the global framework. Internally, at the local site level, lean practitioners are located both at central (local-central) as well as local business unit (local-local) level. The central lean practitioners are responsible for supporting the whole facility with lean deployment. Almost all local-central allocated lean practitioners are representatives in one or more transnational lean process networks regionally and/or as a global process owner.

A new lean practice called Green Kaizen was first initiated and piloted in spring 2018 with good results [23] as part of an innovation project together with a university. 
Green Kaizen is an improvement practice based on a rather simple input-output model with a focus on eliminating environmental waste. The model function as support during the event to map potential improvements in categories such as 'production material', 'energy', 'water', 'emissions' etc. Synergies among lean and green seem obvious from a waste elimination perspective. However, integrating lean and green in practice was new at the production site. With minor time investments, the new improvement method showed financial benefits simultaneously to more environmentally-friendly production. Also, participants in the kaizen events were engaged and empowered by being able to contribute to rather tangible environmental improvements. For example, only by giving attention to the high consumption of plastic gloves during one Green Kaizen event resulted in a decrease in consumption within just one day. It was also stated that the engagement for green improvements was valuable since it was found challenging to achieve a constant engagement for kaizen events in some areas while continuing with a focus on typical lean targets (e.g. lead time, buffer reduction, overall-equipment efficiency, etc.).

\subsection{Lean practice deployment}

Given the positive result of the initial pilots in 2018 [23], the involved team was convinced of the major scale-up potential and decided to deploy the new lean practice further at the production site. The practice was simplified and some minor modifications were made to suit company-specific needs, such as the use of intra-company terminology and layout/branding. The results from the pilots were presented to the top management team of the production site and evolved in a target for deployment. The target was set that all business units should implement at least one Green Kaizen event during 2019 [24]. In the middle of 2019 around $75 \%$ of the planned Green Kaizen were executed in different areas of the production as well as within support functions like labs.

The project team with representatives from both the lean and environment compliance function agreed that Green Kaizen was an improvement tool that should be deployed and managed by the 'lean' organization. The new practice was decided to be incorporated into the global framework categorized as a tool for 'improvement events'. The business process management infrastructure was viewed as the main mechanism to deploy the new lean practice globally to other production sites. It was decided that the practice should be deployed through the same mechanism as other improvement practices in the global framework and managed by that specific business process network. However, in this specific case, there were personnel changes in the network ownership and Green Kaizen as a practice remains to be deployed actively to other production sites.

Further adaptations of the new lean practice were done by codifying instructions by key persons in the team to make the lessons learned explicitly. Also, the need for creating a complete 'product' before deployment was expressed by the team. The intention of finalizing a 'product' was to facilitate future deployment globally. Making a 'product' involved in creating a manual including standards such as templates and tables. Further deployment was on hold until the 'product' was finalized, thus there was no intention to use additional deployment mechanisms before that milestone.

Also, the risk of using the practice without the involvement of required competencies was expressed as a concern if deployed too early. Environmental expertise was said to be a crucial factor for successful events. The environmental competence enabled facilitating and supporting team discussions during the Green Kaizen event, 
reducing the risk of prioritizing environmental improvements that might undermine other requirements (e.g. compliance to legislation), and thus, should be avoided.

\section{Analysis}

The process of practice deployment described in section 3 could be clustered into the four following phases: 'Piloting', 'Branding', 'Codifying Knowledge' and 'Making a Product' (illustrated in Figure 2). These deployment phases are positioned against the dimension of practice adaptation that emerged through the analysis of the data. The dimension of practice deployment is divided into a global (i.e beyond the production site) and local (i.e within the production site) level. The dimension of practice adaptation is a scale of degree between two extremes, low and high. Low practice adaptation is practice replication with no modifications and high practice adaptation is a relatively major modification of the practice (see Figure 2).

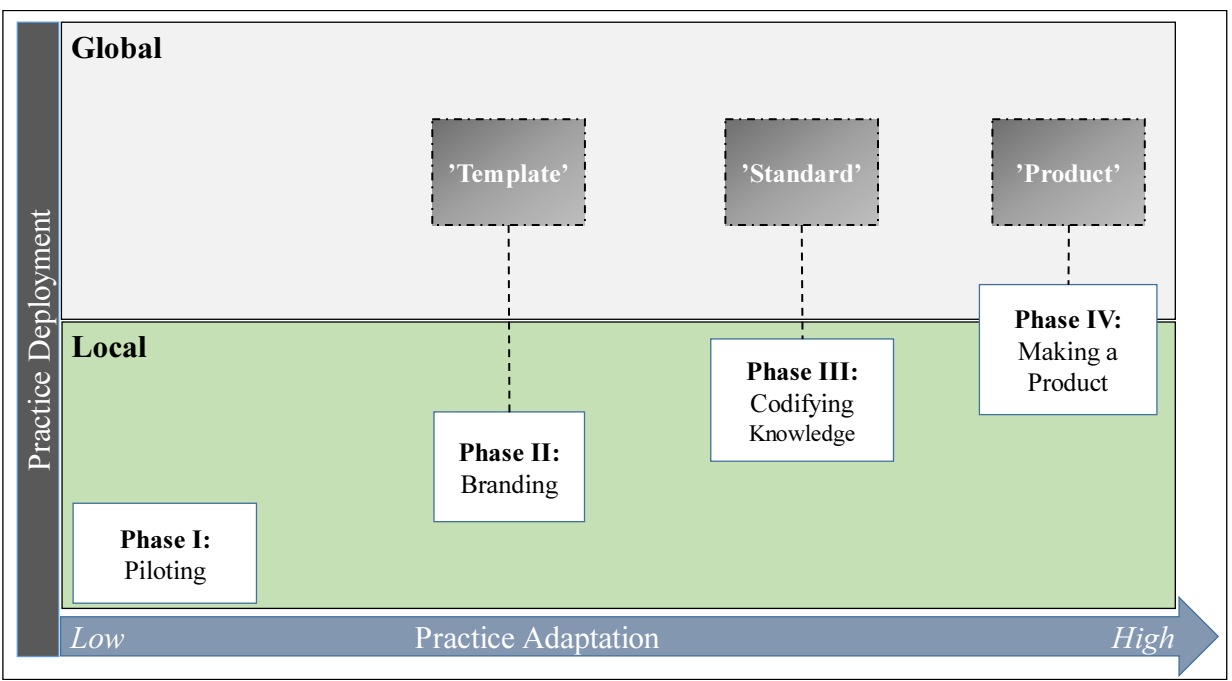

Figure 2. The practice incorporation process is described in four phases (white boxes) alongside the dimensions practice adaptation (bottom). Three conceptual deployment approaches (grey boxes): 'Template', 'Standard' and 'Product' are further explained in section 4.2.

\subsection{Explaining the practice incorporation process with four phases}

Description of the four clustered phases (illustrated in Figure 2), is as follows:

1. 'Piloting': Low adaptation and no deployment since a few production lines were using an externally provided practice. Despite that the respondents did not use an explicit assessment tool, several aspects were considered before determining the potential of deploying the practice locally, such as the proven significant value of the practice and the absence of equivalents in the existing lean framework.

2. 'Branding': Some modifications, such as the use of company terms and colors in the template, were made for the practice to fit the company context and therefore classified as minor adaptations. The intention was to perceive the 
practice as familiar, thus a way for practice internalization. This view is aligned with previous studies where practices are not adopted as finalized solutions but likely to evolve during implementation [18].

3. 'Codifying Knowledge': As explained by involved key persons it was considered important to write down the best practices during the implementation and codifying instructions in guidelines and standards. The knowledge evolved during the various implementations, which were approved by the top site management team at a local level. The decision was pointed out as crucial for practice deployment due to the allocated time for implementation by the production managers.

4. 'Making a Product': This phase is different from the previous in terms of that the view goes beyond standard development based on emerged knowledge from the lean practice implementations. The intention with 'packaging' the available knowledge is mainly on the degree of compatibility with global network infrastructure so that it could be easily transferred to other sites. This includes e.g. creating and translating a manual.

\subsection{Global diffusion of new lean practices}

The starting point of the implementation of the new lean practice was the participation in a research project, where the GPM method was piloted at the case study company (see section 2). Thus, no early involvement of global internal agents was considered necessary. This demonstrates that the exploration of new knowledge was existing locally at the production site. Also, despite the lack of any incentives for deploying the new lean practice globally, it was decided rather early to be the ambition. A co-existence of exploration and exploitation has also been highlighted by Secchi and Camuffo (2016) to be important dimensions in the 'roll-out' process [8].

In the view of how global companies can 'harvest' local innovative lean practices emerging locally in the corporate network is analyzed based on three conceptual bottomup deployment approaches presented here:

Stage A: Template deployment. The results of the pilots were satisfactory and considered successful by the case company and results presented during the research project and in the previous master thesis [23]. The practice modifications had the intention to internalize the practice to the specific company context. The internalization of practices was presented in previous studies, for example as a way to reduce 'stickiness' in implementation and ramp-up [19]. However, since the modification is on the 'company-branding' level, it is common for all production sites, and therefore motivated.

Stage B: Standard deployment. It is unlikely that only a template could embed the necessary knowledge for successful implementation, especially since it was explicitly said that the practice requires environmental engineering expertise. Standards were created as a way to codify the new lean knowledge since only providing the template was considered insufficient when deploying the practice. The importance of the dimension of a "knowledge duplication strategy" has also been presented in a top-down approach [8], [18]. Including local internal stakeholders, such as the top management team at the production site, enabled deployment since an additional deployment mechanism beyond the network infrastructure (BPM) was used. This emphasizes the importance of top 
management commitment and argues for creating standards as a knowledge duplication strategy as well as communication support for internal stakeholders.

Stage C: Product deployment. It was considered to be important to support practitioners with a complete 'product' including tables and templates which later could be incorporated into the existing framework. Despite the expressed intention to simplify further deployment, all practices are made to get adapted when adopted by the recipient [18]. Reasonably local needs are more likely to be embedded in the practice standards unintentionally, which may not be applicable for other production sites. As previously identified by Danese et al. (2017), there is a risk for increased 'stickiness' by the adopting production site when embedding superfluous features in standards transferred bottom-up [19]. The decision to finalize the product might reduce the initial knowledge diffusion due to a lack of involvement in the exploring phase. However, whether that decreases the efficiency of deployment to global levels at a later stage can not be concluded given the scope of this study, and needs to be further investigated.

\section{Discussion}

The contribution of this study is considered to be threefold. First, the paper highlights the bottom-up perspective of lean practice deployment in a global lean management context. Second, the empirical findings indicate that the incorporation process of a new lean practice can be explained in four phases: 'Piloting', 'Branding', 'Codifying Knowledge' and 'Making a product'. The four phases provide a suggestion of how practices are adapted while being deployed locally as well as globally. And third, three conceptual deployment approaches are presented as support for lean practitioners (global and local) to make thoughtful decisions regarding what and how practices should be deployed regarded as the dimension of practice adaptation. The incorporation process may not be an explicit process within a company. Thus, this paper suggests potential influential factors in such a company-specific process, hence, the insight can be valuable for the efficient utilization of intra-organizational resources.

The bottom-up view of lean practice incorporation challenges the common and traditional top-down approach of cascading corporate lean programs as discussed in existing literature see e.g. [8], [17], [27]. This study presents a bottom-up approach to build new organizational lean knowledge by incorporating new lean practices into the existing global framework. A view is that global lean frameworks develop 'organically' through input from the production sites in the corporate network. At the same time, if incorporation processes are insufficient, there is a risk for local misalignments and isolation, which could decrease lean practice diffusion within the corporate group. That, in turn, could impede the opportunities to harvest the local intra-organizational innovation, and thus competitiveness.

The lean practice diffusion process presented in this study relies mainly on a business process network infrastructure, where the networks are vehicles for development. That infrastructure relies on an idealization that the networks are all active and well-functioning. It is unclear what, or if, companies have other processes in place when the networks are inactive. This might indicate a reliance on the BPM structure or unawareness of optional mechanisms to transfer lean knowledge [17]. The intention to further adapt the practice and form standards is consciously hindering an early deployment. This is, however, not surprising since the experienced persons are logically 
most suitable for creating the standards and are aligned with the knowledge duplication strategy highlighted in previous studies [8], [19]. To acknowledge is the variable of incentives to deploy new lean practices in a global lean context. The new practice could even be neglected as innovation and seen as a burden for the global lean offices as a result of the indistinctness of the bottom-up innovation diffusion process. However, statements regarding the global views stretch beyond the frames of this study.

Overall, the transparency to global agents of the new lean practice was partly hindered by the intention of codifying knowledge in standards. 'Making a product' which fits in the global framework might be a duplication of the top-down tactic due to lack of explicit bottom-up processes in the given context. The major empirical insight from the case is that the new lean practice was not solely developed for its users locally but the lean practice was also adapted to align with the current global lean framework. The phases of piloting, branding and codifying knowledge have support in prior research and are not contradicting the existing theory of practice adaptation and knowledge duplication strategy [8], [18]. However, the phase of 'making a product' was beyond viewing the codified lean knowledge as best practice to create a package that can easily be transferred as a 'product' to the customer, which in this case study was global network owners. It may indicate that non-explicit processes of local lean practice deployment in a global context will impede innovation diffusion. However, valid claims about whether that is so cannot be determined based on a single case. It would be interesting to conduct future research to evaluate the deployment efficiency of the three conceptual deployment approaches and evaluate the outcome of each deployment approach.

Thus, harvesting innovation among the corporate group is to assure that the deployment of successful lean practices is encouraged by the production sites. Some innovative lean practices can show the potential to be incorporated into the common global framework for strategic reasons, and thus be particularly important in a time of ongoing industrial transformation. By utilizing the local resources by means to execute pilot and autonomously deploy successful lean practices may contribute to the competitiveness of the company.

\section{Acknowledgment}

The authors are grateful for the AZ personnel assigning time to provide information and company documents for the study.

\section{References}

[1] U. Leyen. European Commission, 2019. Accessed: 29.11.2019. [Online]. Available: https:/ec.europa.eu/commission/sites/beta-political/files/political-guidelines-nextcommission_en.pdf..

[2] T. Netland, Exploring the phenomenon of company-specific production systems: One-best-way or own-best-way?, International Journal of Production Research., vol. 51, 2013, pp. 1084-1097.

[3] M. Rolfsen, S.-S. Kilskar, and N. Valle, We are at day one of a new life: translation of a management concept from headquarter to a production team, Team Performance Management, vol. 20, 2014, pp. 343-356.

[4] B. Kogut and A. Reuben, Multinational Corporations, in International Encyclopedia of Social \& Behavioral Sciences, Elsevier, 2nd ed., 2015, pp. 74-80.

[5] D.-J. Teece, G. Pisano, and A. Shuen, Dynamic capabilities and strategic Management, Strategic Journal, vol. 18, 1997, pp. 509-533. 
[6] J. Bhamu and K.-S. Sangwan, Lean manufacturing: literature review and research issues, International Journal of Operations \& Production Management, vol. 34, 2013, pp. 876-940.

[7] J.-K. Liker, The Toyota Way. McGraw-Hill Education, New York, 2004.

[8] R. Secchi and A. Camuffo, Rolling out lean production systems: a knowledge-based perspective, International Journal of Operations \& Production Management, vol. 36, 2016, pp. 61-85.

[9] OECD/Eurostat, Oslo Manual 2018: Guidelines for Collecting, Reporting and Using Data on Innovation, 4th ed., Luxembourg, 2018.

[10] H. Carvalho, K. Govindan, S.-G. Azevedo, and V. Cruz-Machado, Modelling green and lean supply chains: An eco-efficiency perspective, Resources, Conservation and Recycling, vol. 120, 2017, pp. 75-87.

[11] A. Muñoz-Villamizar, J. Santos, J.-J. Garcia-Sabater, A. Lleo, and P. Grau, Green value stream mapping approach to improving productivity and environmental performance, International Journal of Productivity and Performance Management, vol. 68, 2019, pp. 608-625.

[12] C.-A. Maritan and T.-H. Brush, Heterogeneity and transferring practices: Implementing flow manufacturing in multiple plants, Strategic Management Journal, vol. 24, 2003, pp. 945-959.

[13] T.-H. Netland and E. Sanchez, Effects of a production improvement programme on global quality performance: The case of the Volvo Production System, The TQM Journal, vol. 26, 2014, pp. 188201.

[14] T.-H. Netland, J.-D. Schloetzer, and K. Ferdows, Implementing corporate lean programs: The effect of management control practices, Journal of Operations Management, vol. 36, 2015, pp. 90-102.

[15] C. Andersson and M. Bellgran, On the complexity of using performance measures: Enhancing sustained production improvement capability by combining OEE and productivity, Journal of Manufacturing Systems, vol. 35, 2015, pp. 144-154.

[16] T.-H. Netland and A. Aspelund, Multi-plant improvement programmes: a literature review and research agenda, International Journal of Operations \& Production Management, vol. 34, 2014, pp. 390-418.

[17] K. Demeter and D. Losonci, Transferring lean knowledge within multinational networks, Production Planning and Control, vol. 30, 2019, pp. 211-224.

[18] S.-S. Ansari, J. Reinecke, and A. Spaan, How are practices made to vary? Managing practice adaptation in a multinational corporation, Organization Studies, vol. 35, 2014, pp. 1313-1341.

[19] P. Danese, P. Romano, and S. Boscari, The transfer process of lean practices in multi-plant companies, International Journal of Operations \& Production Management, vol. 37, 2017, pp. 468488 .

[20] M. Bellgran, M. Kurdve, and M. Wiktorsson, Green Performance Map: Handbok, Eskilstuna, 2012.

[21] R.-K. Yin, Case study research: Design and methods, SAGE publications, London, 2009.

[22] P. Eriksson and A. Kovalainen, Qualitative Methods in Business Research, SAGE Publications, London, 2011.

[23] R. Hanna, Kostnadsdrivet förbättringsarbete inom miljö Kostnadsdrivet förbättringsarbete inom miljö - En fallstudie på AstraZeneca, 2018 [in Swedish].

[24] N. Thorne and E. Ekström, Green Kaizen - Verktyget inom Lean med miljö i fokus - En fallstudie om tillämpningen av en ny metod för miljöförbättringsarbete på AstraZeneca. 2019 [in Swedish].

[25] S.-C. Kitto, J. Chesters, and C. Grbich, Quality in qualitative research, Medical Journal of Australia, vol. 188, 2008, pp. 243-246.

[26] D.-A. Gioia, K. G. Corley, and A.-L. Hamilton, Seeking Qualitative Rigor in Inductive Research: Notes on the Gioia Methodology, vol. 16, 2012, pp. 15-31.

[27] S. Boscari, P. Danese, and P. Romano, Implementation of lean production in multinational corporations: A case study of the transfer process from headquarters to subsidiaries, International Journal of Production Economics, vol. 176, 2016, pp. 53-68. 